\title{
Modified Pectoral Nerve Block versus Serratus Block for Analgesia Following Modified Radical Mastectomy: A Randomized Controlled Trial
}

This article was published in the following Dove Press journal: Journal of Pain Research

\author{
Ahmed H Bakeer (D) \\ Khaled M Kamel \\ Ahmed S Abdelgalil (D) \\ Ayman A Ghoneim (D) \\ Ahmed H Abouel Soud \\ Mohamed E Hassan \\ Department of Anesthesia and Pain \\ Management, National Cancer Institute, \\ Cairo, Egypt
}

Correspondence: Ahmed H Bakeer Department of Anesthesia and Pain Management, National Cancer Institute, Mohamed Shokry Street, Agouza, Cairo, Egypt

Tel +20233360906

Email mail@mcs-center.com
Background: Modified pectoral nerves (PECSII) and serratus blocks have been recently used for analgesia in breast surgery, but evidence comparing their analgesic benefits is limited. This prospective randomized, controlled study aims to examine the analgesic efficacy and safety profile of ultrasound-guided PECSII versus serratus blocks in patients undergoing modified radical mastectomy (MRM) for breast cancer.

Patients and Methods: One-hundred and eighty adult females scheduled for MRM were randomly allocated to three groups. PECS group patients received a PECSII block with $30 \mathrm{~mL}$ of bupivacaine $0.25 \%$, whereas SAPB group received a serratus anterior plane block (SAPB) using the same volume of bupivacaine $0.25 \%$ before induction of anesthesia. The control group received general anesthesia alone. Outcomes included 24 hours morphine consumption, intraoperative fentanyl requirements, visual analogue scale (VAS) scores for pain at rest and during movement, time to first rescue analgesia, postoperative nausea and vomiting (PONV), and sedation scores.

Results: Both PECSII and serratus blocks were associated with reduced postoperative morphine consumption compared to the control group $(\mathrm{p}<0.001)$. Both blocks were associated with reduced intraoperative fentanyl requirements, VAS scores, and PONV as compared with the control group. Also, they were associated with prolonged time to first rescue analgesia and better sedation scores in comparison with the control group. However, there were no differences between both blocks for all outcomes.

Conclusion: PECSII and serratus blocks provide similarly adequate analgesia following modified radical mastectomy.

Clinical Trial Registration: NCT02946294.

Keywords: breast cancer, mastectomy, modified radical, analgesics, pectoral nerves, nerve block, pain management, thoracic nerves, morphine

\section{Introduction}

Modified radical mastectomy (MRM) is one of the most common surgeries performed, and one that may be associated with significant acute postoperative pain in breast surgery. ${ }^{1}$ Acute postoperative pain is an independent risk factor in the development of chronic post-mastectomy pain. ${ }^{2}$

Various regional anesthetic procedures have been tried to provide better acute pain control and, consequently, less chronic pain. They can reduce perioperative opiates requirement and thereby decreasing their possible side effects. ${ }^{3}$ These regional procedures include local wound infiltration, thoracic epidural, and thoracic 
paravertebral block (PVB). Currently, a series of new ultrasound (US)-guided interfascial plane blocks have been recommended as safe, easy, and reliable alternatives to the use of thoracic epidural and paravertebral blocks in providing analgesia for patients about to undergo breast surgery. They are named pectoral nerves block type-1 (PECSI), pectoral nerves block type-2 (PECSII), and serratus plane block. ${ }^{4-6}$

Pectoral nerves block type-1 blocks lateral and medial pectoral nerves by injecting the local anesthetic (LA) between pectoralis major muscle (PMm) and pectoralis minor muscle $(\mathrm{Pmm}){ }^{7}$ In PECSII or modified PECSI block, a second injection of LA above serratus anterior muscle in the anterior axillary line is added to block the intercostal nerves II-VI. ${ }^{8}$ Serratus anterior plane block (SAPB) blocks the intercostal nerves II-VI by injection above or below the serratus muscle in the mid-axillary line and spares the pectoral nerves. ${ }^{9}$

We assumed that PECSII could safely provide a better analgesic profile with an opioid-sparing effect than SAPB. We performed this study to evaluate this assumption.

\section{Patients and Methods}

This prospective randomized controlled trial was conducted at the National Cancer Institute, Egypt from October 2016 to December 2018, after being approved by the institute's ethics committee (Approval no.: IRB00004025). It was registered as a clinical trial (Registration No.: NCT02946294). This trial was conducted in accordance with the Declaration of Helsinki. The de-identified data of all participants in the study (including all variables) are available on request from the corresponding author. The study included 180 patients aged 18-60 years, with an American Society of Anesthesiologists (ASA) class II scheduled for unilateral modified radical mastectomy (MRM). After informing the patients about the study design, written informed consents were obtained. Patients with a history of bleeding diathesis (INR $>1.5$ or platelet count $<50 \times 10^{3} / \mathrm{mm}^{3}$ ), relevant drug allergy, opioid dependence, local sepsis, psychiatric illnesses (which may interfere with perception and assessment of pain) were excluded from the study. All patients included in the study were educated on how to report pain on a visual analogue scale (VAS) where $0=$ no pain and $10=$ the worst imaginable pain.

Patients were then randomly allocated into three groups using computer-generated random numbers concealed in sealed opaque envelopes opened the day before surgery after obtaining the signed written consent. PECS
Group patients received a PECSII block with $30 \mathrm{~mL}$ of bupivacaine $0.25 \%$, whereas SAPB Group received a serratus anterior plane block (SAPB) using the same volume of bupivacaine $0.25 \%$ before induction of anesthesia. The Control Group received general anesthesia alone. In the pre-anesthetic room, midazolam was given in a dose of $0.02 \mathrm{mg} / \mathrm{kg} \mathrm{IV}$. All blocks were done under complete aseptic conditions while patients were monitored and receiving oxygen via a fitted face mask.

In PECS Group, US-guided PECSII block was done on the same side of surgery with the patient lying in the supine position with the ipsilateral arm abducted and externally rotated, and the elbow flexed $90^{\circ}$. The 13-6 $\mathrm{MHz}$ transducer (FUJIFILM SonoSite, Inc. Bothell, WA 98021 USA) was put transversely in the ipsilateral clavipectoral triangle - between the clavicle medially and above and the shoulder joint laterally. After identification of the PMm, Pmm, and the plane in between, the probe was tilted caudally to identify the pulsating pectoral branch of the thoracoacromial artery, if not identified, the probe was moved $1-2 \mathrm{~cm}$ caudally and medially. In a caudal tilt, the artery was easily identified in a biconvex space. The skin at the point of entry was infiltrated using lidocaine $1 \%$; then, the needle (disposable spinal needle, K-3 point type LUER-Lock HUB 22G) was advanced in an in-plane technique targeting the space in which the artery is located. Two $\mathrm{mL}$ of dextrose $5 \%$ was injected to confirm the location, produce hydro-dissection, and improve needle visualization. Afterward, $10 \mathrm{~mL}$ of bupivacaine, $0.25 \%$, was injected.

Then, the probe was moved laterally and caudally towards the anterior axillary fold, parallel to the deltopectoral groove, until the serratus muscle appears underneath the Pmm attached to the underlying ribs. The 3rd and fourth ribs and the pleura were then identified. After infiltration of the skin with lidocaine $1 \%$, the needle was advanced in-plane targeting the plane between the serratus and the third rib. Two $\mathrm{mL}$ of dextrose $5 \%$ was injected; then, $20 \mathrm{~mL}$ of bupivacaine $0.25 \%$ was injected. Twenty minutes later, the pinprick test was done to assess the sensory block in the dermatomes T2-T6 compared to the unblocked contralateral side. A delayed sensory loss on the blocked side $>20$ minutes was defined as a failed block. Patients with failed blocks were excluded from the study.

In SAPB Group, a US-guided serratus block was done with the patient in the lateral position, with the side of the surgical side up and the upper limb hanging over the 
patient's head. The ribs were then counted, and when the 4th rib was identified, the high-frequency probe was put over it, in the mid-axillary line in a sagittal plane. The ribs, pleura, and overlying serratus muscle were identified, and the needle was advanced cephalad in-plane until the tip touched the 4 th rib. Afterward, $2 \mathrm{~mL}$ dextrose 5\% was injected; then, $30 \mathrm{~mL}$ of bupivacaine $0.25 \%$ was injected in the plane between the serratus and the 4 th rib. The pinprick test was done and assessed, as described earlier. Patients of the Control group did not receive any preoperative block.

All the staff involved in data collection were blinded to the group assignment. The drugs administered in the regional blocks were prepared according to group randomization by a staff anesthesiologist not related to the patient management or the data collection.

In the operation room, standard monitors were attached. A baseline reading of the heart rate (HR) and blood pressure was recorded. The induction of general anesthesia was carried out using fentanyl $(1 \mu \mathrm{g} / \mathrm{kg})$ IV and propofol ( $2 \mathrm{mg} / \mathrm{kg}$ ) IV. Endotracheal intubation was facilitated by cisatracurium $(0.15 \mathrm{mg} / \mathrm{kg}) \mathrm{IV}$. The lungs were mechanically ventilated to maintain an end-tidal carbon dioxide of $35 \mathrm{mmHg}$. Paracetamol $1 \mathrm{gm} / 100 \mathrm{~mL}$ IV infusion and ketorolac $30 \mathrm{mg}$ IV slowly were given before surgical incision. Anesthesia was maintained by sevoflurane $2 \%$ in $50 \%$ oxygen/air mixture. Additional bolus doses of fentanyl $0.5 \mu \mathrm{g} / \mathrm{kg}$ were given if there was a $20 \%$ rise in the mean arterial pressure (MAP) and/or HR, in comparison to the baseline readings. At the end of the surgery, the muscle relaxant was reversed using neostigmine $(0.04 \mathrm{mg} /$ $\mathrm{kg})$ and atropine $(0.01 \mathrm{mg} / \mathrm{kg})$. After fully awake extubation, all patients were transferred to the post-anesthesia care unit (PACU).

In the first postoperative 24 hours, IV boluses of morphine sulfate were given to maintain $\mathrm{VAS} \leq 3$, as follows: $2 \mathrm{mg}$ repeated two times if required (total three boluses) with at least 10 minutes between each bolus, then $1 \mathrm{mg}$ repeated if necessary with at least 15 minutes between each bolus. Paracetamol $1 \mathrm{gm} / 100 \mathrm{~mL} \mathrm{IV} \mathrm{infusion} \mathrm{was}$ given every 8 hours and ketorolac $30 \mathrm{mg}$ every 12 hours postoperatively.

The total amount of morphine consumed in the first 24 postoperative hours was the primary outcome measure. Secondary outcomes were the intraoperative fentanyl requirements, time to first rescue analgesia and VAS scores at rest and during shoulder movement immediately postoperative (defined as $15 \mathrm{~min}$ post-extubation) and at 1 hour, 4 hours, 8 hours, 12 hours and 24 hours postoperatively. Ramsey sedation score (RSS) was assessed at the same time points. Heart rate and MAP were recorded intraoperatively (1-minute pre-incision, 1-minute postincision) and postoperatively at 1, 4, 8, 12, 24 hours. Postoperative nausea and vomiting (PONV) were rated on a four-point verbal scale (none $=$ no nausea, mild = nausea but no vomiting, moderate $=$ vomiting one attack, severe $=$ vomiting $>$ one attack). PONV was treated by 10mg metoclopramide slowly IV. All other complications such as pneumothorax, local anesthetic systemic toxicity, respiratory depression defined as a respiratory rate $<12$ breaths per minute, urine retention, allergy, or pruritus were recorded. Patients' satisfaction with the analgesic technique was done using a three-point scale $0-2$ in which $(0=$ dissatisfied, $1=$ somewhat satisfied, $2=$ satisfied $)$.

\section{Sample Size}

We presumed that PECSII could reduce opioid consumption by $10 \%$ compared to the serratus block. Forty-eight patients in each group were required to elicit the difference at an alpha level of 0.05 and power of $90 \%$. A $10 \%$ increase of the sample was added to accommodate multiple comparisons and another $15 \%$ for dropouts. Therefore, 60 patients in each group were included.

\section{Statistical Methods}

Statistical analysis was done using IBMC SPSSC Statistics version 22 (IBMC Corp., Armonk, NY, USA). The sample size was estimated using the G*Power@ software (Institut für Experimentelle Psychologie, Heinrich Heine Universität, Düsseldorf, Germany) version 3.1.9.2. Numerical data were expressed as mean and standard deviation or median and range as appropriate. One-way analysis of variance or Kruskal-Wallis test compared three independent groups. For time-related data, repeated-measures ANOVA with mixed models was used for testing time effects and group interaction. Chi-square (or Fisher's Exact) tests tested proportion independence. All post hoc tests were Bonferroni adjusted. All tests were two-tailed. A p-value $<0.05$ was considered significant.

\section{Results}

One-hundred and eighty patients participated in the study; two patients in the control group refused to continue the study, three patients in the PECS group, and two patients in the serratus group were excluded due to failed block. There was no significant difference in the patients' 
demographic data and duration of surgery between all groups (Table 1).

Fewer patients in the PECS and SAPB groups needed morphine injections during the first 24 hours compared to the control group $(\mathrm{p}<0.001)$. Those who requested morphine in the PECS and SAPB groups consumed a single dose of $2 \mathrm{mg}$, while the median consumed dose in the control group was $7 \mathrm{mg}$ (range: $2-12)(\mathrm{p}<0.001)$.

Intra-operative fentanyl requirements were significantly lower in the PECS and SAPB groups compared to the control group, and both groups showed comparable fentanyl consumption $(\mathrm{p}=0.221)$. PECS and SAPB groups were associated with significantly prolonged time to first postoperative analgesic request compared to the control group. However, the time to 1st rescue analgesia was comparable in PECS and SAPB groups $(p=0.768)$ (Table 2$)$.

PECS and serratus groups were each associated with significantly reduced VAS scores during shoulder movement during all assessment times - when compared with the control group $(p<0.001)$. There was no significant difference between the PECS and the serratus groups at all-time points $(p=1.0)$ (Table 3).

Table I Demographic Data and Duration of Surgery

\begin{tabular}{|l|l|l|l|l|}
\hline & $\begin{array}{l}\text { Control } \\
\text { Group } \\
\mathbf{n = 5 8}\end{array}$ & $\begin{array}{l}\text { PECS } \\
\text { Group } \\
\mathbf{n = 5 7}\end{array}$ & $\begin{array}{l}\text { SAPB } \\
\text { Group } \\
\mathbf{n = 5 8}\end{array}$ & $\begin{array}{l}\mathbf{p} \\
\text { value }\end{array}$ \\
\hline Age (years) & $50.4 \pm 9.3$ & $50.8 \pm 8.9$ & $50.9 \pm 6.8$ & 0.952 \\
Weight $(\mathrm{kg})$ & $89.6 \pm 8.2$ & $90.9 \pm 6.9$ & $91.8 \pm 5.3$ & 0.202 \\
Height $(\mathrm{cm})$ & $164.5 \pm 5.2$ & $164.7 \pm 3.6$ & $164.9 \pm 4.0$ & 0.841 \\
Duration of & $152 \pm 37$ & $155 \pm 53$ & $158 \pm 34$ & 0.798 \\
surgery (min.) & & & & \\
\hline
\end{tabular}

Note: Data are presented as mean \pm SD.

Table 2 Postoperative analgesic requirements in the three studied groups

\begin{tabular}{|l|l|l|l|l|}
\hline & $\begin{array}{l}\text { Control } \\
\text { Group } \\
\mathbf{n = 5 8}\end{array}$ & $\begin{array}{l}\text { PECS } \\
\text { Group } \\
\mathbf{n = 5 7}\end{array}$ & $\begin{array}{l}\text { SAPB } \\
\text { Group } \\
\mathbf{n = 5 8}\end{array}$ & $\begin{array}{l}\mathbf{p} \\
\text { value }\end{array}$ \\
\hline $\begin{array}{l}\text { No. of patients requiring } \\
\text { postoperative morphine }\end{array}$ & $44(73.3 \%)$ & $11(19.3 \%)$ & $14(24.1 \%)$ & $<0.001$ \\
\hline $\begin{array}{l}\text { Intraoperative Fentanyl } \\
\text { consumption ( } \mathrm{\mu g})\end{array}$ & $155 \pm 31$ & $94 \pm 14$ & $101 \pm 17$ & $<0.001$ \\
\hline $\begin{array}{l}\text { Time to Ist rescue } \\
\text { analgesia (min.) }\end{array}$ & $17.0 \pm 5.1$ & $\begin{array}{l}343.3 \\
\pm 22.3\end{array}$ & $\begin{array}{l}337.5 \\
\pm 40.6\end{array}$ & $<0.001$ \\
\hline
\end{tabular}

Note: Data are presented as number (\%) or mean \pm SD.
Table 3 VAS Numerical Pain Distress Scale at Rest and During Shoulder Movement in the Three Studied Groups

\begin{tabular}{|c|c|c|c|c|}
\hline & $\begin{array}{l}\text { Control } \\
\text { Group } \\
n=58\end{array}$ & $\begin{array}{l}\text { PECS } \\
\text { Group } \\
n=57\end{array}$ & $\begin{array}{l}\text { SAPB } \\
\text { Group } \\
n=58\end{array}$ & $\begin{array}{l}\mathbf{P} \\
\text { value }\end{array}$ \\
\hline \multicolumn{5}{|l|}{ VAS at rest } \\
\hline $\begin{array}{c}\text { Immediate } \\
\text { postoperative }\end{array}$ & $6(0-10)$ & $0(0-3)$ & $0(0-2)$ & $<0.001$ \\
\hline $\mathrm{Ihr}$ & $3(0-4)$ & $0(0-2)$ & $0(0-2)$ & $<0.001$ \\
\hline $4 \mathrm{hr}$ & $2(0-5)$ & $0(0-2)$ & $0(0-2)$ & $<0.001$ \\
\hline $8 \mathrm{hr}$ & $2(0-5)$ & $0(0-3)$ & $0(0-2)$ & $<0.001$ \\
\hline $12 \mathrm{hr}$ & $2(0-3)$ & $0(0-3)$ & $0(0-2)$ & $<0.001$ \\
\hline $24 \mathrm{hr}$ & $2(0-3)$ & $0(0-2)$ & $0(0-2)$ & $<0.001$ \\
\hline \multicolumn{5}{|c|}{ VAS during shoulder movement } \\
\hline $\begin{array}{c}\text { Immediate } \\
\text { postoperative }\end{array}$ & $8(0-10)$ & $0(0-3)$ & I (0-3) & $<0.001$ \\
\hline $\mathrm{Ihr}$ & $3(I-6)$ & I $(0-3)$ & I (0-3) & $<0.001$ \\
\hline $4 \mathrm{hr}$ & $3(I-6)$ & I $(0-2)$ & I (0-2) & $<0.001$ \\
\hline $8 \mathrm{hr}$ & $3(0-6)$ & I $(0-3)$ & I (0-3) & $<0.001$ \\
\hline $12 \mathrm{hr}$ & $3(2-7)$ & I $(0-3)$ & I (0-3) & $<0.001$ \\
\hline $24 \mathrm{hr}$ & $3(2-7)$ & I $(0-3)$ & I $(0-3)$ & $<0.001$ \\
\hline
\end{tabular}

Note: Data are presented as median (range).

All patients in the PECS and SAPB groups had an RSS of 2 immediately postoperative, while in the control group, $43.1 \%$ had a score of 1 , and $56.9 \%$ recorded a score of $2(p<0.001)$. After that, all patients in the three groups had a score of 2 at 1 , $4,8,12$, and 24 hours postoperatively.

Both PECS and SAPB groups showed significant reduction in PONV, with a frequency of $3.5 \%$ and $6.9 \%$, respectively, compared with $60.3 \%$ in the control group ( $p=0.003$, and $p=0.015$, respectively). The difference between the PECS and SAPB groups was not significant $(p=1.0)$. No cases of pneumothorax, local anesthetic toxicity, or opioid side effects as respiratory depression, pruritus, or urinary retention were recorded among the three groups. All patients of the PECS and SAPB groups were satisfied (score 2) with the postoperative analgesia, while the median score of the Control group was $1(0-2)$.

\section{Discussion}

To our knowledge, this is the first study to compare the analgesic efficacy and safety profile of modified pectoral nerve block (PECSII block) and serratus block for the management of postoperative pain following MRM.

This study demonstrated that PECSII and serratus blocks have comparable analgesic properties in patients undergoing modified radical mastectomy. Both blocks were associated 
with reduced postoperative pain intensity and morphine consumption, intraoperative fentanyl requirement, and PONV, and prolonged analgesia compared to the control group. The two blocks were associated with hemodynamic stability, better sedation scores, and higher satisfaction scores when compared to the control group. The absence of major complications characterizes both blocks.

The PECSII and serratus blocks were compared to other types of regional techniques in breast surgery. PECS block was associated with a better analgesic profile when added to general anesthesia in patients undergoing MRM. It was characterized by lower VAS scores, and reduced intra- and postoperative opioid consumption than general anesthesia alone. In line with the current study, PONV and sedation scores were also lower in the PECS group than in the control group patients. ${ }^{10}$ The same superior analgesic quality was confirmed in patients undergoing immediate reconstruction after MRM. ${ }^{11}$ Syal and Chandel ${ }^{12}$ confirmed the analgesic efficacy of PECS block during MRM, but they found it inferior to paravertebral block. In a more recent randomized trial, PECS block was more effective than erector spinae plane block in patients undergoing unilateral modified radical mastectomy surgery regarding reduction of pain intensity and postoperative opioid consumption. ${ }^{13}$ PECS I combined with SAPB was reported to provide excellent perioperative pain relief following MRM. ${ }^{14}$

PECSII block was compared to a placebo block in patients undergoing mastectomy or tumorectomy in a randomized, double-blind study. The authors reported that patients in the PECSII group experienced significantly less pain with less postoperative opioid requirements. Contrary to the present study, intraoperative sufentanyl requirements were comparable for the PECS and placebo groups. ${ }^{15}$ This difference may be attributed to variation in the type of surgery. About $75 \%$ of their patients underwent lumpectomy with sentinel node dissection, while all patients of the current study had MRM, which is a more extensive and lengthy procedure.

Kulhari et al $^{16}$ compared PECSII block above serratus with thoracic paravertebral block during radical mastectomy. PECSII block was associated with prolonged postoperative analgesia, lower morphine consumption, and lower pain intensity (VAS scores) in the first two postoperative hours. Moreover, it was recently suggested that the PECS block might reduce the incidence of chronic pain after breast surgery. ${ }^{17}$

However, Kamiya et $\mathrm{al}^{18}$ reported different findings with PECSII block in patients undergoing breast cancer surgery. Pain intensity was reduced but not intraoperative remifentanil consumption or postoperative rescue analgesic requirements. This may be due to performing the block after induction of anesthesia with no confirmation of the dermatomal sensory loss and the use of a multimodal perioperative analgesia regimen, including acetaminophen, tramadol, diclofenac and dexamethasone in both groups. The authors suggested that the inability of the PECS block to reach the internal mammary area was the cause of comparable remifentanil consumption with the control group.

In patients undergoing MRM serratus plane block was compared to paravertebral block. The former was effective postoperative analgesic, but, paravertebral block was associated with a longer duration of analgesia and less morphine consumption. ${ }^{19}$ Rahimzadeh et $\mathrm{al}^{20}$ found that serratus block effectively reduced the postoperative opioid usage and prolonged analgesia duration after mastectomy. However, it did not reduce pain scores compared to the control group. This discordance with the current study may be contributed to performing the block postoperatively, while it was done preoperatively in the present study. Also, it was noted that the control group consumed larger doses of postoperative fentanyl PCA than the serratus group, which might reduce the pain scores.

The results of this study suggest that PECSI does not contribute greatly to the analgesic efficacy of the PECSII block during MRM. This may be explained by the fact that MRM does not involve excessive disruption or stretch of the pectoralis muscles and confirms what has been stated in the literature that the PNs are mainly motor nerves. ${ }^{21}$ Nevertheless, the PNs blockade is an important analgesic modality in surgeries affecting substantial stretching of the pectoral muscles, eg, insertion of breast expanders during reconstructive breast cancer surgery or subpectoral prostheses. ${ }^{7,21}$ Its analgesic effect may come mainly from the relaxation of the pectoral muscles after PNs blockade.

In a large retrospective cohort study, Abdallah et al evaluated the benefits of adding PECSI or serratus blocks to conventional opioid-based analgesia in patients undergoing ambulatory breast cancer surgery. The authors reported a comparable reduction of intraoperative fentanyl requirement, postoperative morphine consumption, and pain scores, PONV with prolonged analgesia compared to the control group. This suggests that PECSI produces equal analgesia as the serratus block, which proposed a significant contribution of PNs to pain generated after breast cancer surgery. 
These findings are contradictory to our results. This contradiction may be due to several causes. First, a larger volume of LA $(15-20 \mathrm{~mL})$ is injected between the PMm and Pmm in this study compared to the volume used in our study $(10 \mathrm{~mL})$. This large volume could have been spread to the axilla and blocked the thoracic intercostals nerves. Also, the volume of LA injected in the serratus block $(20-25 \mathrm{~mL})$ in this study is smaller than that used in our study $(30 \mathrm{~mL})$. Thirdly, PECSI could have resulted in a blockade of the thoracic intercostal nerves, as there are reported communications between the PNs and thoracic intercostal nerves. $^{21}$ Fourthly, intraoperative manipulation and stretching of the pectoral muscles may be another source of perioperative myofascial pain that can be relieved by PNs blockade. ${ }^{21}$ Lastly, the type of breast surgery was different; $100 \%$ of our cases had MRM compared to only $13 \%$ in this study.

There are some limitations to this study. The study was not extended to assess the effects of the two blocks on the development of chronic post-mastectomy pain. Also, the lack of a placebo or sham block injection in the control group may be a disadvantage. Further work is required to compare continuous PECS catheter and serratus catheter over 24-48 hours.

In conclusion, US-guided PECSII and serratus block can improve the perioperative analgesia in patients undergoing MRM for breast cancer. Both techniques reduce perioperative opioid requirements and pain intensity and prolong the duration of analgesia with no significant complications.

\section{Acknowledgment}

Thanks to residents Mohammed Gaafar and Mohammed Magdy for their invaluable contribution to proofreading and language editing of this work.

\section{Author Contributions}

We hereby confirm that all authors contributed to data analysis, drafting or revising the article, gave final approval of the version to be published, and agree to be accountable for all aspects of the work.

\section{Disclosure}

The authors report no conflicts of interest in this work.

\section{References}

1. Amaya F, Hosokawa T, Okamoto A, et al. Can acute pain treatment reduce postsurgical comorbidity after breast cancer surgery? A literature review. Biomed Res Int. 2015;2015:1-8. doi:10.1155/2015/641508

2. Wang L, Guyatt GH, Kennedy SA, et al. Predictors of persistent pain after breast cancer surgery: a systematic review and meta-analysis of observational studies. CMAJ. 2016;188(14):E352-E361. doi:10.1503/ cmaj. 151276
3. Garg R, Bhan S, Vig S. Newer regional analgesia interventions (fascial plane blocks) for breast surgeries: review of literature. Indian J Anaesth. 2018;62(4):254. doi:10.4103/ija.IJA_46_18

4. Garg R. Regional anaesthesia in breast cancer: benefits beyond pain. Indian J Anaesth. 2017;61(5):369-372. doi:10.4103/ija.IJA_292_17

5. Sir E, Eksert S, Ince ME, et al. Ultrasound-guided serratus anterior plane block for the treatment of posttraumatic intercostal neuralgia. Am J Phys Med Rehabil. 2019;98(11):e132-e135. doi:10.1097/ PHM.0000000000001121

6. Blanco R, Barrington MJ. Pectoralis and serratus plane blocks. In: Hadzic A, editor. Hadzic's Textbook of Regional Anesthesia and Acute Pain Management. 2nd ed. McGraw-Hill Education; 2017. Available from: accessanesthesiology.mhmedical.com/content.aspx? aid $=1141734765$. Accessed June 8, 2020.

7. Blanco R. The "pecs block": a novel technique for providing analgesia after breast surgery. Anaesthesia. 2011;66(9):847-848. doi:10.1111/j.1365-2044.2011.06838.x

8. Blanco R, Fajardo M, Parras Maldonado T. Ultrasound description of Pecs II (modified Pecs I): a novel approach to breast surgery. Rev Esp Anestesiol Reanim. 2012;59(9):470-475. doi:10.1016/j. redar.2012.07.003

9. Blanco R, Parras T, McDonnell JG, Prats-Galino A. Serratus plane block: a novel ultrasound-guided thoracic wall nerve block. Anaesthesia. 2013;68(11):1107-1113. doi:10.1111/anae.12344

10. Bashandy GMN, Abbas DN. Pectoral nerves I and II blocks in multimodal analgesia for breast cancer surgery: a randomized clinical trial. Reg Anesth Pain Med. 2015;40(1):68-74. doi:10.1097/ AAP.0000000000000163

11. Wang K, Zhang X, Zhang T, et al. The efficacy of ultrasound-guided type II pectoral nerve blocks in perioperative pain management for immediate reconstruction after modified radical mastectomy: a prospective, randomized study. Clin J Pain. 2018;34(3):231-236. doi:10.1097/AJP.0000000000000529

12. Syal K, Chandel A. Comparison of the postoperative analgesic effect of paravertebral block, pectoral nerve block and local infiltration in patients undergoing modified radical mastectomy: a randomised double-blind trial. Indian J Anaesth. 2017;61(8):643-648. doi:10.4103/ ija.IJA_81_17

13. Altıparmak B, Korkmaz Toker M, Uysal Aİ, Turan M, Gümüș Demirbilek S. Comparison of the effects of modified pectoral nerve block and erector spinae plane block on postoperative opioid consumption and pain scores of patients after radical mastectomy surgery: a prospective, randomized, controlled trial. J Clin Anesth. 2019;54:61-65. doi:10.1016/j.jclinane.2018.10.040

14. Wang W, Song W, Yang C, et al. Ultrasound-guided pectoral nerve block i and serratus-intercostal plane block alleviate postoperative pain in patients undergoing modified radical mastectomy. Pain Physician. 2019;22(4):E315-E323.

15. Versyck B, van Geffen G-J, Van Houwe P. Prospective double blind randomized placebo-controlled clinical trial of the pectoral nerves (Pecs) block type II. J Clin Anesth. 2017;40:46-50. doi:10.1016/j. jclinane.2017.03.054

16. Kulhari S, Bharti N, Bala I, Arora S, Singh G. Efficacy of pectoral nerve block versus thoracic paravertebral block for postoperative analgesia after radical mastectomy: a randomized controlled trial. Br J Anaesth. 2016;117(3):382-386. doi:10.1093/bja/aew223

17. De Cassai A, Bonanno C, Sandei L, Finozzi F, Carron M, Marchet A. PECS II block is associated with lower incidence of chronic pain after breast surgery. Korean J Pain. 2019;32(4):286-291. doi:10.3344/ kjp.2019.32.4.286

18. Kamiya Y, Hasegawa M, Yoshida T, Takamatsu M, Koyama Y. Impact of pectoral nerve block on postoperative pain and quality of recovery in patients undergoing breast cancer surgery: a randomised controlled trial. Eur $J$ Anaesthesiol. 2018;35(3):215-223. doi:10.1097/EJA.0000000000000762 
19. Gupta K, Srikanth K, Girdhar KK, Chan V. Analgesic efficacy of ultrasound-guided paravertebral block versus serratus plane block for modified radical mastectomy: a randomised, controlled trial. Indian $J$ Anaesth. 2017;61(5):381-386. doi:10.4103/ija.IJA_62_17

20. Rahimzadeh P, Imani F, Faiz SHR, Boroujeni BV. Impact of the ultrasound-guided serratus anterior plane block on post-mastectomy pain: a randomised clinical study. Turk J Anestesiol Reanim. 2018;46 (5):388-392. doi:10.5152/TJAR.2018.86719
21. Woodworth GE, Ivie RMJ, Nelson SM, Walker CM, Maniker RB Perioperative breast analgesia: a qualitative review of anatomy and regional techniques. Reg Anesth Pain Med. 2017;42(5):609-631. doi:10.1097/AAP.0000000000000641

\section{Publish your work in this journal}

The Journal of Pain Research is an international, peer reviewed, open access, online journal that welcomes laboratory and clinical findings in the fields of pain research and the prevention and management of pain. Original research, reviews, symposium reports, hypothesis formation and commentaries are all considered for publication. The manuscript

Submit your manuscript here: https://www.dovepress.com/journal-of-pain-research-journal management system is completely online and includes a very quick and fair peer-review system, which is all easy to use. Visit http:// www.dovepress.com/testimonials.php to read real quotes from published authors. 